Jarek Kurnitski, Juha Jokisalo, Jari Palonen, Kai Jokiranta, and Olli Seppänen. 2004. Efficiency of electrically heated windows. Energy and Buildings, volume 36, number 10, pages 1003-1010. doi:10.1016/j.enbuild.2004.06.007.

(C) 2004 Elsevier Science

Reprinted with permission from Elsevier. 


\title{
Efficiency of electrically heated windows
}

\author{
Jarek Kurnitski*, Juha Jokisalo, Jari Palonen, Kai Jokiranta, Olli Seppänen \\ HVAC-Laboratory, Helsinki University of Technology, P.O. Box 4400, Hut 2015, Finland
}

\begin{abstract}
This study defined, derived and calculated the efficiency of electrical energy use in electrically heated windows which may be used for improving thermal comfort near glazing. In a cold climate, a warm glass surface is a unique possibility for thermal conditioning. The effects of surface and outdoor temperatures and the $U$-value of the window on the efficiency of a heated window were analyzed. The calculated results were compared to previously measured ones. The efficiency of a common heated window with a $U$-value of $1.1 \mathrm{~W} / \mathrm{m}^{2} \mathrm{~K}$ was about $78 \%$ at an outdoor temperature of $-10^{\circ} \mathrm{C}$. The highest efficiency of $89 \%$ was calculated for a highly insulated window. Efficiency was proportional to the outdoor temperature and practically independent of the inner surface temperature of the window, the effect of which was less than $1 \%$. The correlation of the calculated efficiencies shows that efficiency is primarily dependent on the $U$-value of the unheated window and can be expressed with very good accuracy for engineering purposes by a simple linear equation of the $U$-value. The results show that heated glazing is an efficient method for thermal conditioning when properly used.
\end{abstract}

(C) 2004 Elsevier B.V. All rights reserved.

Keywords: Electrically heated windows; Warm glass surface; Thermal conditioning

\section{Introduction}

The efficiency of electrically heated window panes which are designed for improving thermal distribution in a room is analyzed in this paper. In recent years electrically heated windows with a heat output controllable within the range of $50-600 \mathrm{~W} / \mathrm{m}^{2}$ have become available as standard products. They are used as comfort devices, i.e. they do not usually replace other heat sources. In a cold climate, a warm window surface presents unique possibilities for thermal conditioning. Cold windows with a poor $U$-value have always caused drafts and asymmetrical radiation. This is especially so when the glazing is high, and in this case even radiators positioned on the floor cannot stop the formation of drafts.

The principle of a heated window is very simple: an electrical current is switched to the selective layer of a common pane; no additional layers are used, Fig. 1. Basically, the entire glazing unit can be heated and may even be used as a primary heat source. To achieve the optimal use of energy and for reasons of economy, the glazing can be divided into unheated and heated zones. The location and dimensioning of the zones are discussed [1]. When properly located, the horizontal heated zones will avoid drafts and asymmetrical radiation heat transfer caused by the cold glass surface.

\footnotetext{
* Corresponding author. Tel.: +358-9-451-3609; fax: +358-9-451-3418. E-mail address: jarek@cc.hut.fi (J. Kurnitski).
}

The objective of the study is to determine the efficiency of heated windows with respect to electrical energy use. As a heated window is a mixture of a heating device and a window, first, a relevant definition for efficiency is needed. When a general equation for efficiency is derived, previously measured results are compared to the calculated efficiencies. The effect of the surface and outdoor temperatures and the $U$-value of the window on the efficiency of the heated window are shown. The results may be utilized as the basis for design principles for heated windows.

\section{Formulation of $U$-values and efficiency}

The $U$-value is commonly used to describe conduction losses in building envelope parts, i.e. for wall structures without internal heat gains. In such walls, heat flux is constant (in the steady state) in every layer. In a heated window, electrical heating power is switched to the selective layer of the pane. This means that the heat fluxes in the inner and outer panes are not equal and have commonly reverse directions. Thus, the $U$-value which has physical meaning is to be defined based on the heat flux from the outer surface, as shown in Fig. 2. It should be noticed that the $U$-value stated for the inner surface would have a negative value.

$$
U^{\text {off }}=\frac{Q_{\text {out }}^{\text {off }}}{T_{\text {in }}-T_{\text {out }}}, \quad U^{\text {on }}=\frac{Q_{\text {out }}^{\text {on }}}{T_{\text {in }}-T_{\text {out }}}
$$




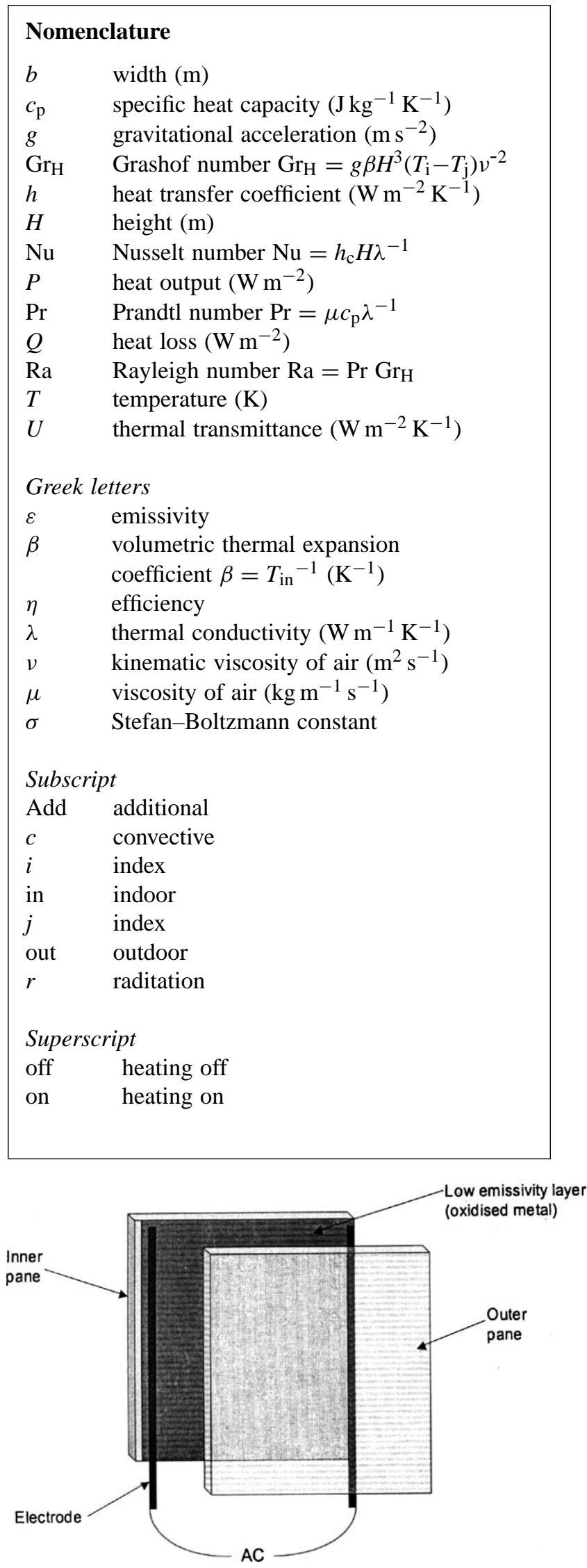

Fig. 1. The principle of electrically heated window.

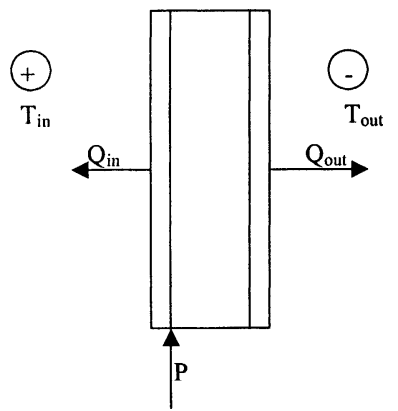

Fig. 2. Heat fluxes in the heated window. $P$ is electrical heat output to the selective layer and $Q_{\text {in }}$ heat flux from the inner surface to indoors $\left(\mathrm{W} / \mathrm{m}^{2}\right)$.

where $U$ is $U$-value ( $\left.\mathrm{W} / \mathrm{m}^{2}, \mathrm{~K}\right)$, superscript 'off' refers to an unheated window (a common window or heated window switched off) and 'on' to a heated window, $Q_{\text {out }}$ is total heat loss, i.e. heat flux from the outer surface $\left(\mathrm{W} / \mathrm{m}^{2}\right)$ and $T_{\text {in }}-T_{\text {out }}$ is the difference between the indoor and outdoor temperatures.

$U^{\text {on }}$ is dependent on heat output rate $P$. However, its definition (Eq. (1)) is justified as it gives the total heat loss through the window. There is no definition available for the efficiency that has become established in use. It does not seem relevant to use the effectiveness of a heating device for a heated window. Effectiveness $Q_{\text {in }} / P$ will almost always have a value of less than $50 \%$. As we are speaking about windows with a heating feature, we are basically interested in additional heat loss $Q_{\text {Add }}$ caused by heating

$Q_{\text {Add }}=Q_{\text {out }}^{\text {on }}-Q_{\text {out }}^{\text {off }}$

Unfortunately, $Q_{\text {Add }}$ cannot be used as a general performance factor because it is strongly dependent on the heat output rate $P$. The more the window is heated, the higher the value of $Q_{\text {Add }}$ is. Thus, the efficiency should be defined in relation to the heat output rate $P$.

The efficiency can be derived by comparing two different heating setups which are shown in Fig. 3. These setups can also be used for experimental measuring of the efficiency. In Fig. 3, the heated window is combined with convective heating where heat is introduced directly into the air volume. In the first setup there is convective heating only and in the second setup, in addition, the window is heated. The heat loss through the walls is set to zero $(Q=0)$ as this term is the same in both setups and will cancelled out in the derivation of efficiency, as can be seen from Eq. (3).

The efficiency can be expressed as the difference between the convective heat terms needed to maintain the same indoor temperature in relation to the electrical heat output $P$ $\left(Q_{\text {off }}-Q_{\text {on }}=P\right.$ means $\left.\eta=1\right)$.

$\eta=\frac{Q^{\text {off }}-Q^{\text {on }}}{P}$

By expanding the terms in Eq. (3) by substituting the heat balance of indoor air and the heated window shown in Fig. 3, one obtains 
1) Unheated window

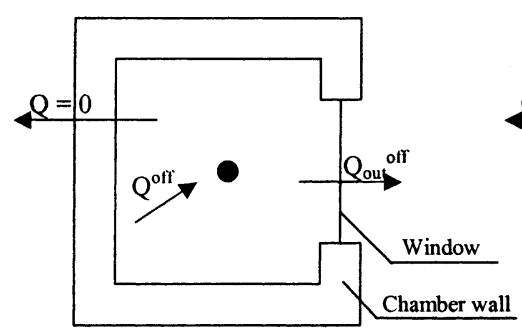

$Q^{\text {off }}-Q_{\text {out }}^{\text {off }}=0$
2) Heated window

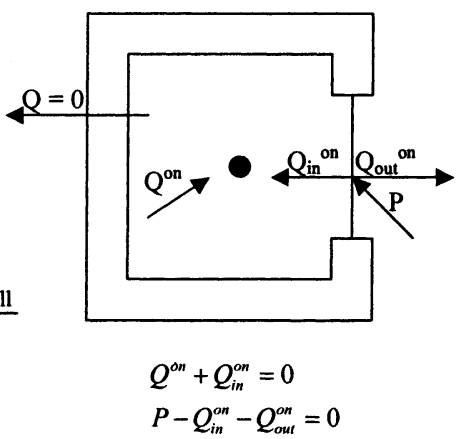

Fig. 3. Derivation and measuring the efficiency by comparing the additional heat loss caused by electrical heating of the window to case with convective heating and unheated window. (1) Heat balance of a fully convective heating where convective heat is introduced directly into air. (2) Heated window and positive or negative convective heat output for maintaining the same indoor air temperature as in (1), and heat balance for air and heated window.

$$
\begin{aligned}
\eta & =\frac{Q^{\text {off }}-Q^{\text {on }}}{P}=\frac{Q_{\mathrm{out}}^{\text {off }}+Q_{\mathrm{in}}^{\text {on }}}{P}=\frac{Q_{\mathrm{out}}^{\text {off }}+P-Q_{\mathrm{out}}^{\mathrm{on}}}{P} \\
& =1-\frac{Q_{\mathrm{out}}^{\mathrm{on}}-Q_{\mathrm{out}}^{\mathrm{off}}}{P}
\end{aligned}
$$

The last form of Eq. (4) can be stated directly, based on an additional heat loss in the heated window: the efficiency is equal to 1 minus the additional heat loss in relation to the electrical heat output. The second expression in Eq. (4) gives a useful formulation: efficiency is the proportion of the electrical heat output $P$ which is used to cover the heat losses of the window and for the heating of the room. Furthermore, the derived efficiency has two important properties making it possible to use it as a general performance factor that describes the energy performance of the heated window in all conditions:

- Efficiency shows how much of the of the electrical power is used to cover the heat losses of the window and for heating the room (expressed as a percentage).

- Efficiency is approximately the same for the same window type regardless of the electrical power rate.

\section{Calculation procedure of $U$-values and efficiency}

The heat transfer process in a heated window is basically similar to heat transfer in a common window. The only dif- ference in energy balance is an additional term of electrical power. Fig. 4 shows the RC-network model for a common triple-glazing type window.

Energy balance equations for each unknown temperature $T$ taking into account the notations shown in Fig. 4 become

$$
\left\{\begin{array}{l}
\left(T_{2}-T_{1}\right) U_{2}+\left(h_{\mathrm{c} 1}+h_{\mathrm{r} 1}\right)\left(T_{\mathrm{in}}-T_{1}\right)=0 \\
\left(T_{1}-T_{2}\right) U_{2}+\left(h_{\mathrm{c} 3}+h_{\mathrm{r} 3}\right)\left(T_{3}-T_{2}\right)=-P \\
\left(T_{4}-T_{3}\right)\left(h_{\mathrm{c} 4}+h_{\mathrm{r} 4}\right)+\left(h_{\mathrm{c} 3}+h_{\mathrm{r} 3}\right)\left(T_{2}-T_{3}\right)=0 \\
\left(T_{\text {out }}-T_{4}\right) h_{\text {out }}+\left(h_{\mathrm{c} 4}+h_{\mathrm{r} 4}\right)\left(T_{3}-T_{4}\right)=0
\end{array}\right.
$$

where temperature $T$ is the surface temperature for the inner pane and the average temperature of the other two panes, $h_{\mathrm{c}}$ is the convective heat transfer coefficient on surfaces and for the space between the panes, $h_{\mathrm{r}}$ is the radiation heat transfer coefficient respectively, and $U_{2}$ is the thermal transmittance of the inner pane. To solve Eq. (5) an iterative procedure is needed as heat transfer coefficients have nonlinear behavior. Radiation heat transfer coefficients

$h_{\mathrm{r}}=\frac{\sigma}{\left(1 / \varepsilon_{i}\right)+\left(1 / \varepsilon_{j}\right)-1} \frac{T_{i}^{4}-T_{j}^{4}}{T_{i}-T_{j}}$

where $h_{\mathrm{r}}$ is the radiation heat transfer coefficient between facing surfaces $i$ and $j\left(\mathrm{~W} / \mathrm{m}^{2} \mathrm{~K}\right), \sigma$ Stefan-Boltzmann constant $5.67 \times 10^{-8}\left(\mathrm{~W} / \mathrm{m}^{2} \mathrm{~K}^{4}\right), T_{i}$ and $T_{j}$ absolute temperatures on surfaces $(\mathrm{K})$ and $\varepsilon_{i}$ and $\varepsilon_{j}$ emissivity factors of the surfaces. The same emissivity factors are used for heated and unheated windows because the temperature levels are

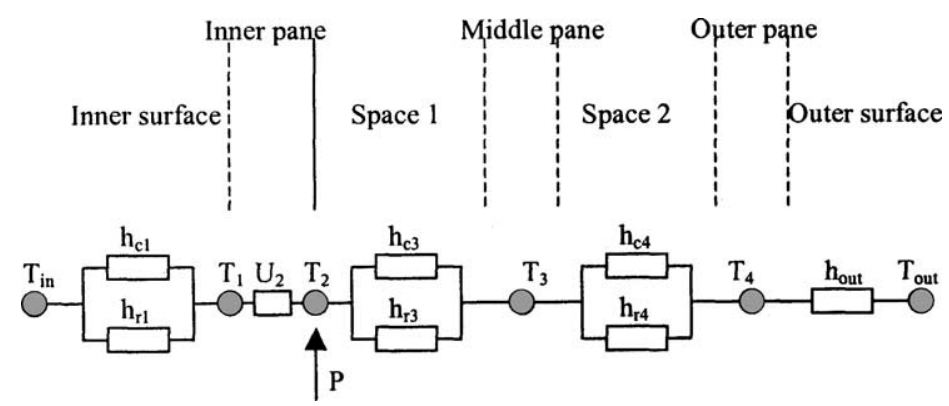

Fig. 4. RC-network model of a triple-glazing window. In an unheated case $P=0$. 
relatively low in both cases (the temperature for heated windows does not commonly exceed $40^{\circ} \mathrm{C}$ ).

The values of convective heat transfer coefficients on surfaces depend on indoor and outdoor boundary conditions. We considered free convection on an inner surface without any disturbance caused by indoor airflows and a constant value for the overall heat transfer coefficient on the outer surface. The convective heat transfer coefficient on an inner surface for the turbulent flow region [2].

$h_{\mathrm{c}}=0.10 \operatorname{Ra}_{H}^{1 / 3} \frac{\lambda}{H}$

where $R a$ is Rayleigh number, $\lambda$ thermal conductivity of air $(\mathrm{W} / \mathrm{m}, \mathrm{K})$ and $H$ height of the window (m). A constant overall heat transfer coefficient $h_{\text {out }}=25 \mathrm{~W} / \mathrm{m}^{2} \mathrm{~K}$ is used [3]. Comapred to EN 673 [4], Eqs. (6) and (7) tend to give slightly higher thermal resistance for the inner surface $(0.16$ versus $0.13 \mathrm{~m}^{2} \mathrm{~K} / \mathrm{W}$ at rating conditions for windows with $U=1.1 \mathrm{~W} / \mathrm{m}^{2} \mathrm{~K}$ ), but the constant value used for the outer surface is the same.

The correlation equation for convective heat transfer in the space between the panes should apply for studied height and width ratio and $R a$ number. In this study, the equation by Elsherbiny et al. [5] was used, the performance of which was shown in [6] by $U$-value measurements of a krypton-filled window

$\begin{aligned} N u & =\left[1+\left(0.0227 R a^{0.438}\right)^{18}\right]^{1 / 18}, \\ \frac{H}{b} & =80, \quad R a<3 \times 10^{4}\end{aligned}$

where Nusselt number $N u=h_{\mathrm{c}} H / \lambda$ is the dimensionless convective heat transfer coefficient and $b$ the space between the panes (m).

\section{Calculation of efficiency}

The following window and boundary conditions are considered:

- A double- or triple-glazing type window with $15 \mathrm{~mm}$ space between the panes.

- The height of the panes is $1.3 \mathrm{~m}$.

- A low emission selective layer on the outside surface of the inner pane with emission factor $\varepsilon=0.04$ and emission factor for the other surfaces is $\varepsilon=0.84$.

- Thermal transmittance of the inner pane $U_{2}=0.8 / 0.004$ $=200 \mathrm{~W} / \mathrm{m}^{2} \mathrm{~K}$.

- An indoor air temperature of $20^{\circ} \mathrm{C}$ and an outdoor temperature within the range of -20 to $+10^{\circ} \mathrm{C}$

\subsection{Inner surface temperature}

The choice of an appropriate temperature for the inner surface of the inner pane $T_{1}$ (facing the room) is illustrated in Table 1. A surface temperature of $25-30^{\circ} \mathrm{C}$ can be rec-
Table 1

Heat output to the room as a function of temperature difference between surface temperature $T_{1}$ and indoor temperature calculated with Eqs. (6) and (7)

\begin{tabular}{lc}
\hline $\begin{array}{l}\text { Temperature difference } \\
\text { (surface-indoor), }\left({ }^{\circ} \mathrm{C}\right)\end{array}$ & $\begin{array}{l}\text { Heat output to the room } \\
\left(\mathrm{W} / \mathrm{m}^{2}\right)\end{array}$ \\
\hline 0 & 0 \\
5 & 32.8 \\
10 & 72.0 \\
20 & 162 \\
\hline
\end{tabular}

ommended as the comfort temperature because the surface is not perceived as being cold when touched, and the asymmetrical radiation temperature difference is low. This temperature range also seems to be most often used in practice.

The effect of the temperature of the inner surface on the efficiency is shown in Fig. 5 for a double-glazing window with three surface temperatures. This window has a selective layer with emission factor $\varepsilon=0.2$ and the $U$-value is within the range of $1.97-1.73 \mathrm{~W} / \mathrm{m}^{2} \mathrm{~K}$ at an outdoor temperature of -20 to $+10^{\circ} \mathrm{C}$ respectively. The indoor temperature is $20^{\circ} \mathrm{C}$. Fig. 5 shows a significant outdoor temperature dependency for the efficiency. The optimal surface temperature in respect of efficiency is a function of outdoor air temperature. However, the effect of the surface temperature is less than $1 \%$ in efficiency.

\subsection{Comparison to convective or radiator heating}

The efficiency of a heated window depends on the heating system used in the unheated case. The heating solution may have an effect on the convection on the surface of the window. In this study Eq. (7), which is an equation for free convection without any disturbance caused by indoor airflows,

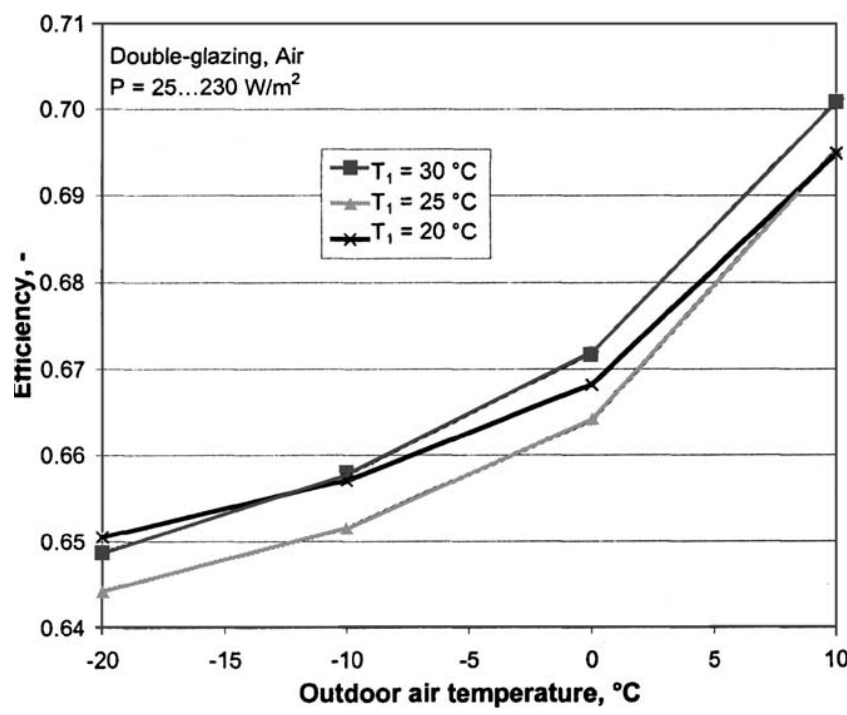

Fig. 5. The dependency of the efficiency on outdoor air temperature and inner surface temperature in the case of a double-glazing window with $U$-value of $1.8 \mathrm{~W} / \mathrm{m}^{2} \mathrm{~K}$ at rating conditions. 
is used for the inner window surface in both the heated and unheated cases. Eq. (7) is probably valid for radiant floor heating, but is not valid for radiator heating. To compare a heated window with radiator heating, it is necessary to use a higher convective heat transfer coefficient, one which is caused by the convection airflow of a radiator. Khalifa and Marshall [7] give the following equation for a window surface with radiator heating

$h_{\mathrm{c}}=8.07\left(T_{\text {in }}-T_{1}\right)^{0,11}$

when Eq. (9) is used instead of Eq. (7) for an unheated window, the efficiency of the window shown in Fig. 5 is increased by about $8 \%$. The increase is the same for a similar triple-glazing window with a $U$-value of $1.3 \mathrm{~W} / \mathrm{m}^{2} \mathrm{~K}$. The following values are given at $-10^{\circ} \mathrm{C}$ outdoor air temperature (being almost the same at $-20^{\circ} \mathrm{C}$ temperature) and a $25^{\circ} \mathrm{C}$ surface temperature:

$\eta=65 \% \rightarrow 73 \%\left(h_{\mathrm{c}}=2.5 \rightarrow 10.2\right) \quad$ double-glazing

$\eta=76 \% \rightarrow 84 \%\left(h_{\mathrm{c}}=2.2 \rightarrow 9.2\right) \quad$ triple-glazing

\subsection{Low emission windows}

In the following, Eq. (7) is used for the convection heat transfer coefficient in all the cases. Therefore, the heated window is compared in all the cases to fully convective heating. The efficiency and $U$-values at varying outdoor temperature are shown in Figs. 6 and 7 for two common window types at a $25^{\circ} \mathrm{C}$ inner surface temperature. The double-glazed window filled with krypton actually shows a slightly lower $U$-value at rating conditions $\left(0^{\circ} \mathrm{C}\right.$ outdoor temperature) relative to the triple-glazed window with air between the panes. However, the $U$-value of the double-glazed window strongly increases at lower outdoor temperatures

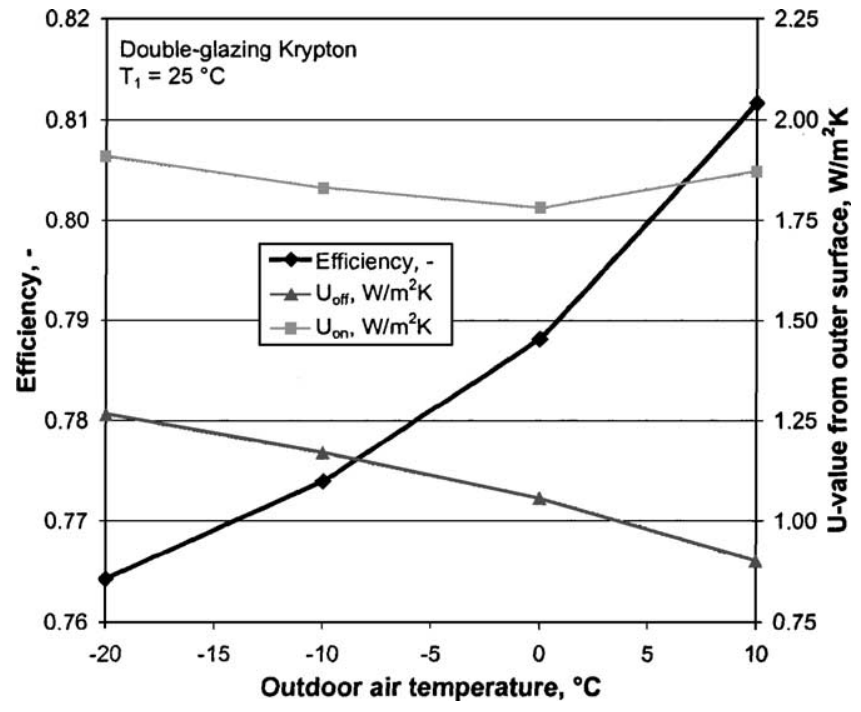

Fig. 6. The efficiency and $U$-values at varying outdoor temperature for double-glazed window filled with krypton.

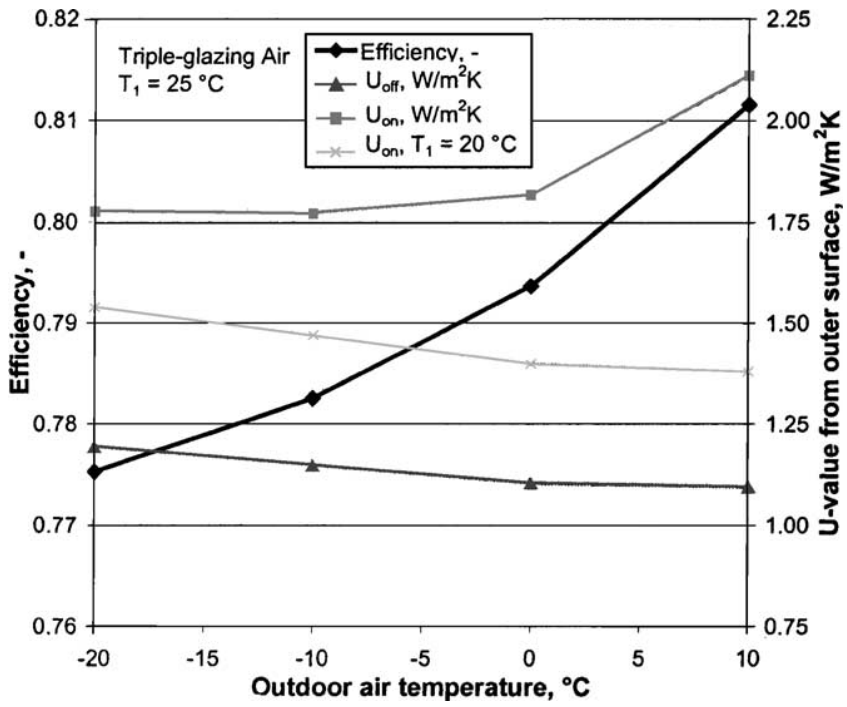

Fig. 7. The efficiency and $U$-values at varying outdoor temperature for triple-glazed window with air.

and the efficiency is lower respectively. To show the behavior of $U_{\mathrm{on}}$, which is dependent on electrical heat output $P$, $U_{\text {on }}$ is also shown for a triple-glazed window with an inner surface temperature of $20^{\circ} \mathrm{C}$.

The variation of efficiency is only about $2-3 \%$ when considering the outdoor temperature range of -20 to $0^{\circ} \mathrm{C}$.

An essential way of reducing heat losses and increasing efficiency is to use highly insulated windows. The highest calculated efficiency is shown in Fig. 8 for a triple-glazed window with two low emission selective layers $\varepsilon=0.04$ and with a krypton fill. In this case, the efficiency is close to $90 \%$ and the dependency on outdoor air temperature is slightly lower than when compared to previous cases.

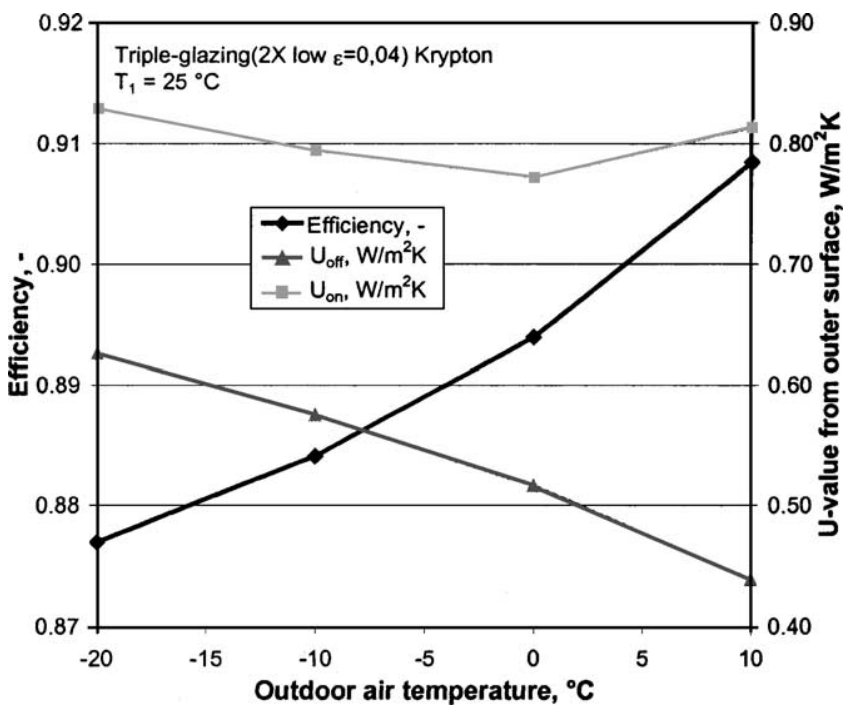

Fig. 8. The efficiency and $U$-values for highly insulated triple-glazed window. 


\subsection{Comparison to measured results}

Two different preliminary measurement results for triple-glazing are available. The first measurements of $U$-values and efficiency were carried out by the Finnish Research Center VTT and these were then repeated by Ihalainen [8] in another laboratory. Experimental results for triple-glazing similar to the one shown in Fig. 7 were between 92 and $93 \%$ (at $0,-10$ and $-20^{\circ} \mathrm{C}$ outdoor temperature) in the measurements by VTT and about $70 \%$ (at 0 and $-10^{\circ} \mathrm{C}$ outdoor temperature) in the measurements by Ihalainen, both reported [8]. Ihalainen suspected the reliability of his measurements due to the massive floor of the test room, which possibly did not reach equilibrium condition during the test. The measurements by VTT were considered reliable.

The differences between the two prelimnar experiment and calculation results are significant. The calculated results of $78-79 \%$ in this study (showed in Fig. 7) are between the results of these two experiments.

\subsection{General expression of efficiency}

The results show that efficiency is practically independent of the inner surface temperature of the window, the effect of which was less than $1 \%$ (Fig. 5). At the same time, efficiency is proportional to the outdoor air temperature. When all the calculated results are plotted against the $U$-value of an unheated window, the linear correlation shown in Fig. 9 can be drawn. Fig. 9 shows the efficiencies of double and triple-glazed windows (all results from Figs. 5-7) and for highly insulated window (results from Fig. 8). All efficiencies and $U$-values are plotted for $+10,0,-10$ and $-20^{\circ} \mathrm{C}$

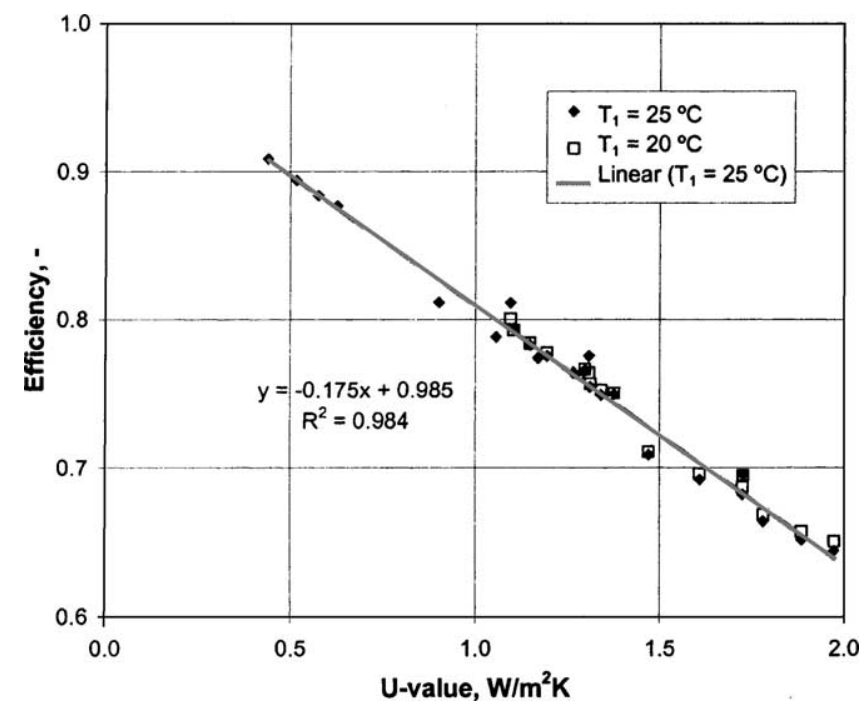

Fig. 9. The efficiencies of double and triple-glazed windows filled with air and krypton plotted against $U$-value of unheated window at $+10,0$, -10 and $-20^{\circ} \mathrm{C}$ outdoor temperatures and at 25 and $20^{\circ} \mathrm{C}$ inner pane surface temperatures. outdoor temperatures and for 25 and $20^{\circ} \mathrm{C}$ inner pane surface temperatures. It should be noted that the $U$-values and efficiencies are for the specific outdoor air temperatures (only some of the points are at rating conditions), which means that both the $U$-values and efficiencies are outdoor air temperature dependent, as shown in earlier figures.

According to the results in Fig. 9, efficiency can be expressed with very good accuracy for engineering purposes by a simple linear equation

$\eta=0.985-0.175 U$

where $U$ is the $U$-value of an unheated window at a specific outdoor temperature. Eq. (10) shows an error of 0.015 at $U=0$ as efficiency should be 1 at $U=0$. Basically, this linear equation cannot be exact due to non-linearity in the convective and radiation heat transfer between the panes and on the outer surfaces. Eq. (10) applies for any outdoor air temperature within the range $\left[-20 ;+10^{\circ} \mathrm{C}\right]$ studied due to outdoor temperature dependent $U$-value. If a $U$-value only at rating conditions is known, the efficiency is obtained at rating conditions and the variation caused by the outdoor temperature dependency of the $U$-value cannot be estimated.

\section{Mathematical interpretation of efficiency formulas}

Simple and accurate correlation of the efficiency (Eq. (10)) calls for further study into the behavior of formulas used for calculation of efficiency. Therefore, it is of special interest to find out any possibility of simplifying the formulas to form one similar to Eq. (10). This is carried out for a double-glazed window shown in Fig. 6.

The efficiency is defined by Eq. (3). Expanding the terms in Eq. (3) the efficiency can be shown as a function of heat output rate, temperatures and heat transfer coefficients

$$
\begin{aligned}
\eta & =1-\frac{1}{P}\left[Q_{\text {out }}^{\text {on }}-Q_{\text {out }}^{\text {off }}\right] \\
& =1-\frac{1}{P}\left[Q_{\text {out }}^{\text {on }}-U^{\text {off }}\left(T_{\text {in }}-T_{\text {out }}\right)\right]
\end{aligned}
$$

with the notations of Fig. 4 Eq. (11) becomes

$$
\begin{aligned}
\eta= & -\frac{1}{P}\left[h_{\text {out }}\left(\left(\frac{T_{\text {out }} h_{\text {out }}+T_{2}\left(h_{\mathrm{c}, 3}^{\text {on }}+h_{\mathrm{r}, 3}^{\text {on }}\right)}{h_{\text {out }}+h_{\mathrm{c}, 3}^{\text {on }}+h_{\mathrm{r}, 3}^{\text {on }}}\right)-T_{\text {out }}\right)\right. \\
& -\frac{1}{\left(1 / h_{\text {out }}\right)+\left(1 /\left(h_{\mathrm{c}, 1}^{\text {off }}+h_{\mathrm{r}, 1}^{\text {off }}\right)\right)+\left(1 /\left(h_{\mathrm{c}, 3}^{\text {off }}+h_{\mathrm{r}, 3}^{\text {off }}\right)\right)} \\
& \left.\times\left(T_{\text {in }}-T_{\text {out }}\right)\right]
\end{aligned}
$$

The electrical heat output rate $P$ and temperature of the inner pane can be calculated from an RC-network model of a double-glazing window as follows

$$
P=\left(h_{\mathrm{c}, 1}^{\mathrm{on}}+h_{\mathrm{r}, 1}^{\mathrm{on}}\right)\left(T_{1}-T_{\mathrm{in}}\right)+\frac{h_{\mathrm{out}}\left(h_{\mathrm{c}, 3}^{\mathrm{on}}+h_{\mathrm{r}, 3}^{\mathrm{on}}\right)}{h_{\mathrm{out}}+h_{\mathrm{c}, 3}^{\text {on }}+h_{\mathrm{r}, 3}^{\text {on }}}\left(T_{2}-T_{\mathrm{out}}\right)
$$




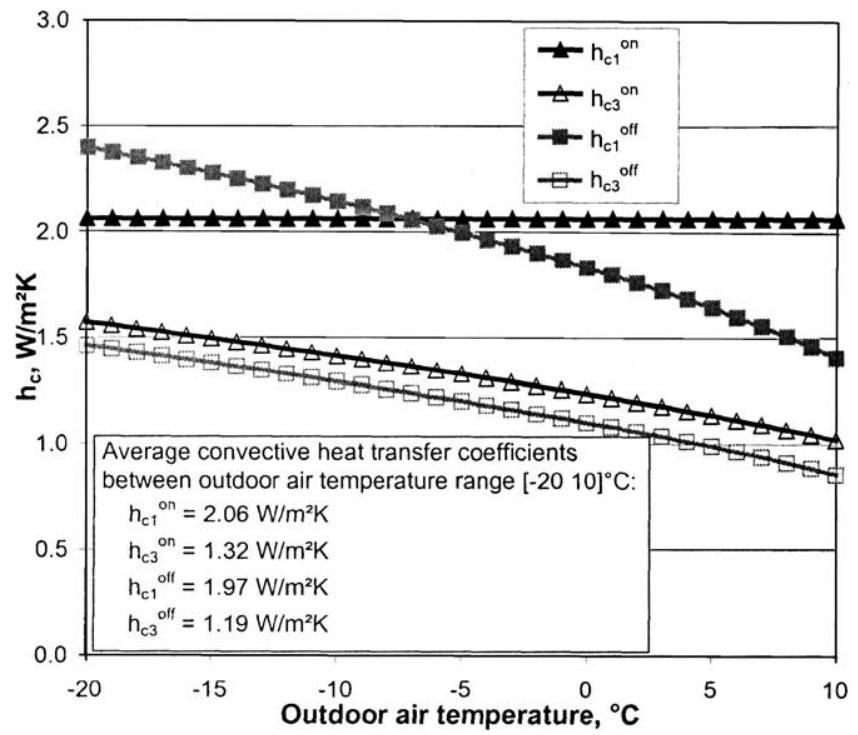

Fig. 10. The dependency of the convective heat transfer coefficients on outdoor air temperature for a double -glazing window filled with krypton. Superscript 'on' refers to heated window and 'off' unheated window.

$T_{2}=T_{1}+\frac{\left(h_{\mathrm{c}, 1}^{\mathrm{on}}+h_{\mathrm{r}, 1}^{\mathrm{on}}\right)\left(T_{1}-T_{\mathrm{in}}\right)}{U_{2}}$

The heat transfer coefficients in Eqs. (12)-(14) are defined by Eqs. (6)-(8). Temperature dependence of the convective and radiation heat transfer coefficients is studied with the RC-network model shown in Chapter 3. A double-glazed window filled with krypton is considered using the boundary conditions specified in Chapter 4. In addition, the surface temperature of the inner pane is set at $25^{\circ} \mathrm{C}$.

The calculated convective and radiation heat transfer coefficients are shown in Figs. 10 and 11. The convective heat

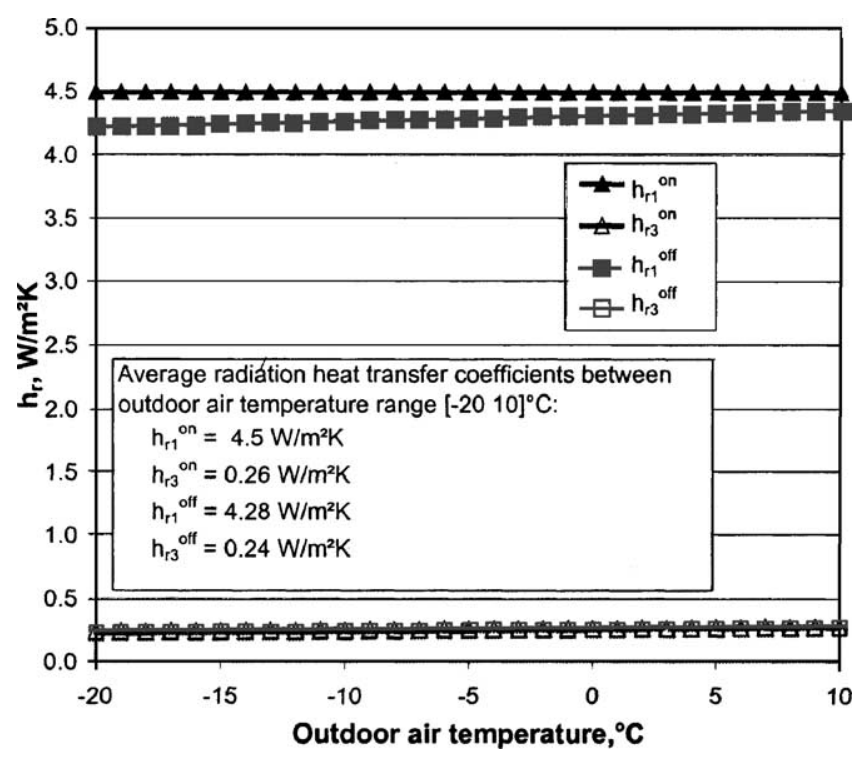

Fig. 11. The dependency of the radiation heat transfer coefficients on outdoor air temperature.

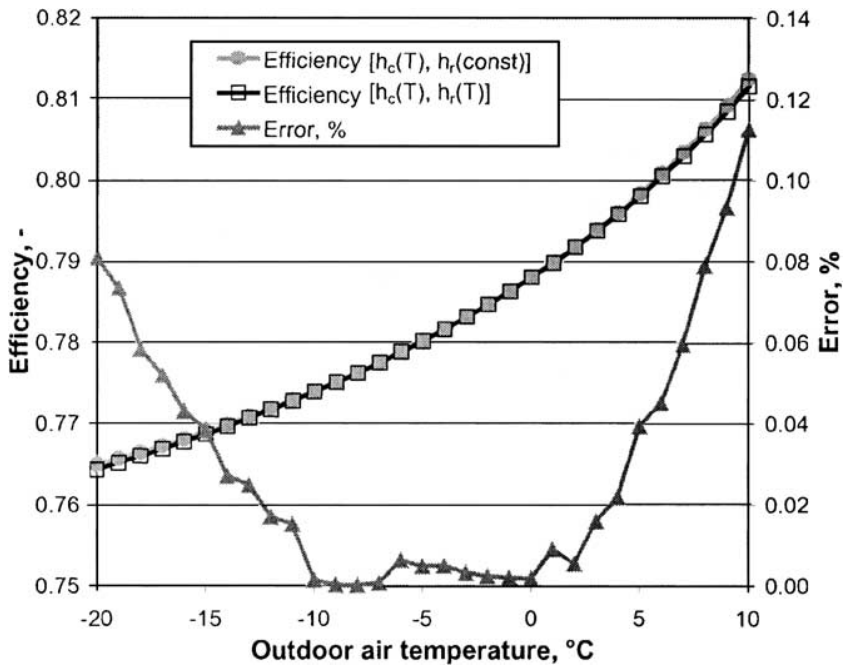

Fig. 12. The dependency of the efficiency on accuracy of the radiation heat transfer coefficients. Efficiency $\left[h_{\mathrm{c}}(T), h_{\mathrm{r}}\right.$ (const)]: the constant radiation heat transfer coefficients and the temperature dependent convective heat transfer coefficients. Efficiency $\left[h_{\mathrm{c}}(T), h_{\mathrm{r}}(T)\right]$ : all heat transfer coefficients temperature dependent.

transfer coefficient for the inner surface of the heated pane is constant because the temperature of the pane is fixed.

The radiation heat transfer coefficient for the inner surface of the heated pane is constant. Temperature dependence of the other radiation heat transfer coefficients is also insignificant, Fig. 11.

By substituting Eqs. (13) and (14) and constant heat transfer coefficients into Eq. (12), the expression of the efficiency can be simplified. Using the average radiation and convective heat transfer coefficients presented in Figs. 10 and 11 with a $25^{\circ} \mathrm{C}$ surface temperature for the inner pane, the efficiency can be given as a function of the outdoor air temperature. Simplifying the efficiency with the commercial Mathematica 4.2 code, the equation tends to

$$
\eta\left(T_{\text {out }}\right) \cong 0.748+\frac{1.693}{47.234-T_{\text {out }}}
$$

where $T_{\text {out }}$ is in ${ }^{\circ} \mathrm{C}$. Calculating efficiency with constant heat transfer coefficients will cause some inaccuracy relative to the results of more exact temperature dependent heat transfer coefficients. The constant values of the heat transfer coefficients used are average values shown in Figs. 10 and 11 . The error caused by the constant radiation heat transfer coefficients is shown in Fig. 12, and the error caused by constant convective and radiation heat transfer coefficients in Fig. 13.

In all, error due to constant heat transfer coefficients seems to be insignificant, not more than $1 \%$ within the range of interest, thus, the simplification is justified. Calculating the efficiency with Eq. (15), the additional inaccuracy is less than $0.09 \%$. When only radiation heat transfer coefficients are constant, the error is actually less than $0.1 \%$. These errors are less than expected, but it is obvious that the error in the separate coefficients cancel each other out in Eq. (12). 


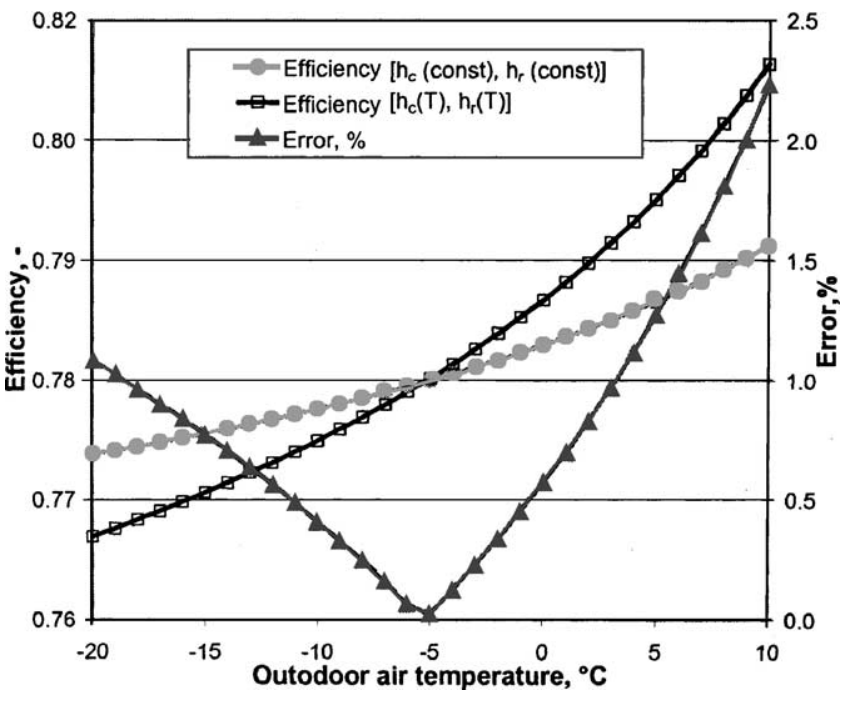

Fig. 13. The dependency of the efficiency on accuracy of the heat transfer coefficients. [ $h_{\mathrm{c}}$ (const), $h_{\mathrm{r}}$ (const)]: constant heat transfer coefficients. $\left[h_{\mathrm{c}}(T), h_{\mathrm{r}}(T)\right]$ : temperature dependent heat transfer coefficients.

Naturally these constant coefficients and efficiency results are valid only for the fixed window-type with the boundary conditions specified above.

\section{Conclusions}

(1) The efficiency of the electrical energy use of heated windows is defined as the proportion of the electrical heat output which is used to cover the heat losses from the window and from the heating of the room. The formulation, derivation and calculation procedure of the efficiency is given.

(2) The efficiency of a common heated window with a $U$-value of $1.1 \mathrm{~W} / \mathrm{m}^{2} \mathrm{~K}$ was about $78 \%$ at $-10^{\circ} \mathrm{C}$ outdoor temperature. The highest efficiency value of $89 \%$ was calculated for a highly insulated window.

(3) Comparison to measured results of efficiency shows significant differences both between two different experiments carried out previously and the calculation results. The calculated results of $78-79 \%$ are between the results of the two previously conducted experiments. This shows how difficult is to carry out sufficiently accurate measurements and the obvious need to repeat the measurements in the future.

(4) The efficiency is inversely proportional to the $U$-value of an unheated window. Efficiency values showed a slight dependency on outdoor air temperature as the $U$-value is outdoor air temperature dependent. Efficiency is practically independent of the inner surface temperature of the window, the effect of which was less than $1 \%$. The correlation of the calculated efficiencies for various window types at different outdoor and surface temperatures shows that efficiency is primarily dependent on the $U$-value of the unheated window and can be expressed with very good accuracy for engineering purposes by a simple linear equation of $U$-value (Eq. (10)) which applied to any outdoor air temperature within the range $\left[-20 ;+10^{\circ} \mathrm{C}\right]$ studied.

(5) It is shown that efficiency formulas may be simplified for a given window-type by the use of constant heat transfer coefficients. The error caused by constant heat transfer coefficients did not exceed $1 \%$ within the outdoor temperature range of $\left[-18 ;+3{ }^{\circ} \mathrm{C}\right]$.

(6) Calculated efficiency values of about $80 \%$ for common window-types show that heated glazing is an effective comfort device for thermal conditioning when properly used.

\section{Acknowledgements}

The Finnish National Technology Agency TEKES, E-Glass Ltd. and Fortum Heat and Power Ltd. are gratefully acknowledged for funding this research.

\section{References}

[1] J. Kurnitski, J. Jokisalo, J. Palonen, O. Seppänen, Improving thermal comfort by electrically heated windows, in: Proceedings of the 4th International Conference on Cold Climate Heating, Ventilation and Air-Conditioning, Cold Climate HVAC 2003, 15-18 June 2003, Trondheim, Norway, CD-Rom, $10 \mathrm{pp}$.

[2] F. Incropera, D. DeWitt, 1990, Fundamentals of Heat and Mass Transfer, third ed. Singapore: John Wiley \& Sons.

[3] D. Loveday, A. Taki, Outside surface resistance: proposed new value for building design, CIBSE A: Building Services Engineering Research Technology 19 (1) (1998) 23-29.

[4] EN 673. Glass in building-determination of thermal transmittance ( $U$-value)-calculation method, CEN, 1997.

[5] S.M. Elsherbiny, G.D. Raithby, K.G.T. Hollands, Heat transfer by natural convection across vertical and inclined air layers, ASME Journal of Heat Transfer 104 (1982) 96-102.

[6] U. Larsson, B. Moshfegh, M. Sandberg, Thermal analyses of super insulated windows (numerical and experimental investigations), Energy and Buildings 29 (1999) 121-128.

[7] A.J.N. Khalifa, R.H. Marshall, Validation of heat transfer coefficients on interior building surfaces using a real-sized indoor test cell, International Journal of Heat and Mass Transfer 33 (10) (1990) 22192236.

[8] P. Ihalainen, Sähkölasielementin lämmönsiirtymismalli ja ominaisuudet (The heat transfer model and properties of electric glass, Master's thesis in Finnish with an english abstract). Diplomityö. Espoo: Teknillinen korkeakoulu, Sovellettu termodynamiikka, 1999. 